\title{
Dietary patterns are related to cognitive functioning in elderly enriched with individuals at increased risk for Alzheimer's disease
}

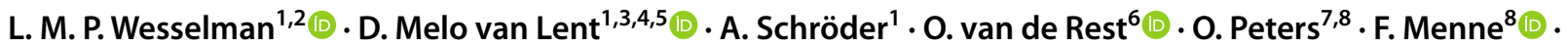

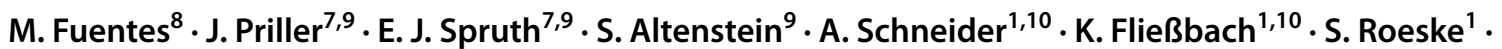 \\ S. Wolfsgruber, ${ }^{10} \cdot$ L. Kleineidam ${ }^{1,10} \cdot$ A. Spottke ${ }^{1,11} \cdot$ V. Pross $^{12} \cdot$ J. Wiltfang ${ }^{13,14} \cdot$ R. Vukovich $^{13,14} \cdot$ A. K. Schild ${ }^{1,15}$. \\ E. Düzel ${ }^{16,17}$. C. D. Metzger ${ }^{16,17,18} \cdot$ W. Glanz ${ }^{16} \cdot$ K. Buerger $^{19,20} \cdot$ D. Janowitz ${ }^{20} \cdot$ R. Perneczky ${ }^{19,21,22,23} \cdot$ M. Tatò $^{19}$.

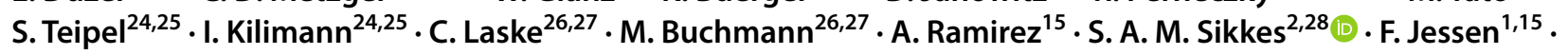 \\ W. M. van der Flier ${ }^{2,29}$ (i) $\cdot$ M. Wagner ${ }^{1,10}$ (i)
}

Received: 8 October 2019 / Accepted: 22 April 2020 / Published online: 29 May 2020

(c) The Author(s) 2020

\begin{abstract}
Purpose To investigate cross-sectional associations between dietary patterns and cognitive functioning in elderly free of dementia.

Methods Data of 389 participants from the German DELCODE study (52\% female, $69 \pm 6$ years, mean Mini Mental State Score 29 \pm 1 ) were included. The sample was enriched with elderly at increased risk for Alzheimer's disease (AD) by including participants with subjective cognitive decline, mild cognitive impairment (MCI) and siblings of AD patients. Mediterranean and MIND diets were derived from 148 Food Frequency Questionnaire items, and data-driven patterns by principal component analysis (PCA) of 39 food groups. Associations between dietary patterns and five cognitive domain scores were analyzed with linear regression analyses adjusted for demographics (model 1), and additionally for energy intake, BMI, other lifestyle variables and APOe4-status (model 2). For PCA-derived dietary components, final model 3 included all other dietary components.

Results In fully adjusted models, adherence to Mediterranean and MIND diet was associated with better memory. The 'alcoholic beverages' PCA component was positively associated with most cognitive domains. Exclusion of MCI subjects $(n=60)$ revealed that Mediterranean and MIND diet were also related to language functions; associations with the alcoholic beverages component were attenuated, but most remained significant.

Conclusion In line with data from elderly population samples, Mediterranean and MIND diet and some data-derived dietary patterns were related to memory and language function. Longitudinal data are needed to draw conclusions on the putative effect of nutrition on the rate of cognitive decline, and on the potential of dietary interventions in groups at increased risk for $\mathrm{AD}$.
\end{abstract}

Keywords Cognition $\cdot$ Dementia $\cdot$ Mediterranean diet $\cdot$ MIND diet $\cdot$ Dietary patterns

\section{Abbreviations}

AD Alzheimer's disease

IQR Interquartile range

L.M.P. Wesselman and D. Melo van Lent contributed equally.

Electronic supplementary material The online version of this article (https://doi.org/10.1007/s00394-020-02257-6) contains supplementary material, which is available to authorized users.

L. M. P. Wesselman

1.wesselman@amsterdamumc.nl

Extended author information available on the last page of the article
MCI Mild cognitive impairment

MIND Mediterranean-DASH Intervention for Neurodegenerative Delay

PCA Principal component analysis

\section{Introduction}

The number of people living with dementia is increasing worldwide due to the aging of the population [1]. With a total of 46 million people living with dementia worldwide in 2015 , this number is estimated to increase to 131.5 million 
by 2050 [2]. As no effective treatment for dementia exists, research on modifiable risk factors is critically important to derive health recommendations and preventive interventions. A healthy lifestyle has been suggested to be one of the modifiable risk factors for cognitive decline and dementia, and prevention studies, therefore, increasingly focus on lifestyle and cognition [3].

Nutrition is one of the lifestyle factors that could prevent or delay cognitive decline and dementia $[4,5]$. It has been suggested that specific foods (e.g., e.g., fatty fish [6-10], red wine [6-8]) are positively associated with cognition, but this is not consistently reported [11]. Moreover, foods are usually not consumed in isolation. A dietary pattern comprises the intake of multiple foods and nutrients in combination. Also, investigating dietary patterns may be more informative for public health purposes, such as the development of foodbased dietary guidelines. It has, therefore, been suggested that relationships between food intake and cognition should be evaluated by taking into account dietary patterns, rather than the intake of single food or nutrients [12].

Several dietary patterns have been established, such as the Mediterranean diet and Mediterranean-DASH Intervention for Neurodegenerative Delay (MIND) diet [13]. The Mediterranean diet comprises a high intake of whole grains, fruits, vegetables, fish and oils, while limiting the intake of fat, salt, alcohol, dairy and meat [14]. Adherence to the Mediterranean diet has been associated with a lower risk for cognitive decline, dementia, and AD [13]. The MIND diet is a modified hybrid of the Dietary Approach to Systolic Hypertension diet (DASH, aiming to reduce blood pressure) and Mediterranean diet, reflecting the most compelling scientific evidence on foods and nutrients that protect the brain $[15,16]$. Compared to the Mediterranean diet, the MIND diet was defined to encourage healthy brain aging, e.g., e.g., promoting the intake of berries and green leafy vegetables, while limiting the intake of animal-based and highly saturated fat foods. Adherence to the MIND diet was found to be associated with lower incidence of AD [16], cognitive decline $[13,15,17,18]$ and subjective memory complaints [19].

The relationships between greater adherence to these diets and better cognition, slower cognitive decline and decreased risk for dementia could not always be replicated (e.g., e.g., [20-22]). Methodological challenges such as the sensitivity of outcome measures, the most sensitive time periods in life course and the true adherence of cultural diverse populations to the predefined diets might have contributed to these inconsistent findings [23]. A complementary strategy for the analysis of dietary patterns is a bottom-up approach, using data-driven methodologies to identify underlying dietary patterns of the specific population under study [24]. For example, a Japanese study found that a dietary pattern characterized by high intake of soybean products, vegetables and dairy products and a low intake of rice was associated with reduced risk for dementia [25]. In a Swedish sample, the 'prudent' pattern, characterized by vegetables, fruit, oil and fish, was associated with less decline in MMSE [26] and in an American sample, a pattern characterized by higher intakes of amongst others salad dressing, several vegetables, fruit, nuts, fish and poultry, and a lower intake of high-fat dairy products, red meat, organ meat, and butter was associated with lower risk for AD [27].

Most studies on cognition and diet have been conducted in general population-based samples and could lead to primary prevention recommendations. However, studies in individuals at increased risk for $\mathrm{AD}$, e.g., e.g., subjects who report or show symptoms of cognitive decline $[28,29]$ may be particularly informative. These samples are expected to include more subjects with AD pathology, which could be counteracted by certain nutrients or diets, to be leveraged for secondary prevention. A recent study in memory-clinic patients with subjective cognitive decline (SCD), a group known to be at increased risk for $\mathrm{AD}$ [28], found a positive association between the 'high-Veggy' dietary pattern, characterized by fruit, vegetables, fish, and fibers, with global cognition using a data-driven approach [30].

We aimed to cross-sectionally investigate the associations between dietary patterns and cognition in a memory clinic-based sample of German elderly free of dementia. More specifically, the association between adherence to the Mediterranean diet, MIND diet and data-derived dietary patterns and memory, language, executive functions, working memory and visuospatial functions was investigated.

\section{Methods}

\section{Design}

The DZNE-Longitudinal Cognitive Impairment and Dementia Study (DELCODE) is an observational longitudinal memory clinic-based multicenter (10 sites) study of the German Center for Neurodegenerative Diseases (DZNE) in Germany [31]. With the aim to study risk factors and early markers of Alzheimer's disease, DELCODE is enrolling subjects with subjective cognitive decline (SCD), patients with mild cognitive impairment (MCI) or mild Alzheimer's dementia (AD), as well as first-degree relatives of patients with a documented diagnosis of $\mathrm{AD}$ and controls. All patient groups (SCD, MCI, AD) are referrals, including self-referrals. Controls and relatives of AD patients are recruited by standardized public advertisement. DELCODE participants receive extensive clinical and neuropsychological assessments, MRI and PET measurements, and biomaterials are collected. The study has been performed in accordance with the ethical standards laid down in the 1964 Declaration of Helsinki and 
its later amendments. Local ethical approval was obtained at each DELCODE site. All participants gave written informed consent. DELCODE is registered at the German Clinical Trials Register (DRKS00007966; 04/05/2015).

\section{Participants}

\section{Selection}

From the DELCODE interim baseline data release $(N=687)$, all 395 participants free of dementia with dietary data available, were selected. Participants did not differ from nonparticipants regarding sex, education and MMSE score, but were slightly younger $(69.3 \pm 5.6$ vs. $71.2 \pm 5.7, p<0.01)$. We excluded individuals with abnormal total energy intakes, i.e., below $2092 \mathrm{~kJ}(500 \mathrm{kcal})$ or above $20,920 \mathrm{~kJ}$ (5000 kcal) $(n=4)$ or with missing nutrition data over $20 \%(n=2)$. This resulted in a study sample of 389 individuals (52\% female, mean age $69 \pm 6$ years; mean Mini Mental State Examination score $29 \pm 1$ ).

\section{Diagnostic groups}

At study inclusion, the CERAD neuropsychological test battery was used to measure cognitive performance [31]. SCD was defined by the presence of subjectively reported decline in cognitive functioning with concerns as expressed to the physician of the memory center and a test performance of better than -1.5 standard deviations (SD) below the age, sex, and education-adjusted normal performance on all subtests of the CERAD neuropsychological battery. Controls and AD-relatives were also required to have normal cognitive performance in all CERAD subtests. The MCI group consisted of individuals with demographically adjusted performance below $-1.5 \mathrm{SD}$ on the delayed recall trial of the CERAD word-list episodic memory tests.

The current sample included 146 subjects with SCD (MMSE 29.2 \pm 1.1 ), 60 patients with MCI (MMSE $28.0 \pm 1.8$ ), 35 first-degree relatives of AD dementia patients (MMSE 29.3 \pm 1.1 ) and 148 healthy controls (no cognitive impairment; MMSE 29.5 \pm 0.8 ).

\section{Measurements}

\section{Cognition}

At baseline, participants underwent an extensive neuropsychological assessment to capture cognitive functioning [32]. Cognitive data were transformed into five standardized cognitive domain scores: (1) memory (Alzheimer's Disease Assessment Scale-Cognitive Subscale word list: trial 1, 2, 3, delayed recall and recognition; Free and Cued Selective
Reminding Test (FCSRT): free recall and cue efficiency; Wechsler Memory Scale: logical memory 1+2; Consortium to Establish a Registry for Alzheimer's Disease (CERAD): figure savings, Symbol-Digit-Modalities Test (SDMT): incidental learning, Face Name Test); (2) language (verbal fluency: groceries and animals, Boston Naming Test (20 items); FCSRT: naming); (3) executive functioning (Trail Making Test A + B; Number Cancelation, SDMT, Flanker Task); (4) working memory (Digit Span Forward + Backward, FCSRT: interference task (Serial $3 \mathrm{~s}$ ); and (5) visuospatial functioning (Clock copying + drawing, CERAD Figure copying).

\section{Nutritional intake}

Nutritional intake was assessed using the German version of the European Prospective Investigation of Cancer Food Frequency Questionnaire (EPIC-FFQ [33, 34]), a comprehensive 148-item, semi-quantitative self-report. The FFQ includes questions on type and amount of food items, frequency of consumption and methods for food preparation. Items were described either with household units or with usual portion sizes, visualized by illustrations. These data were used to calculate the nutritional intake in frequency per day/week and grams/day (calculations conducted by the German Institute of Nutritional Research (DIfE)). This resulted in 254 variables with information on either frequency per day/week or intake in grams/day.

\section{Dietary patterns}

\section{Mediterranean diet score}

The original Mediterranean diet score is based on food groups (i.e., not food items) consumed by a traditional Greek population [35]. The diet score is a guideline to be used to rank people according to their adherence to the dietary guideline, not an exact diet. Numerous studies from diverse study populations across the globe have replicated the diet score based on the food items available on the assessment method in use [36]. The Mediterranean diet score included nine food groups (g/day): vegetables, legumes, fruits and nuts, dairy products, cereals, meat and poultry, fish, alcohol, and ratio of monounsaturated fatty acids and saturated fat [35]. Sex-specific medians based on the current study population were used as cut-offs. For healthy and unhealthy food groups, a score of 1 was given when intake was, respectively, equal or above the cut-off (e.g., vegetables) or below the cut-off (e.g., saturated fatty acids). Only for alcohol, a range indicating adherence was used. See Supplementary Table 2 for the cut-off per food group. Scores on all food groups were summed to calculate the total Mediterranean diet score, ranging from 0 to 9 , with 9 indicating highest adherence to the Mediterranean diet guideline. 


\section{MIND diet score}

The group of Professor M.C. Morris at Rush University Medical Center created the MIND diet by specifically including food groups that were shown to be related to brain health. These food groups were based on the published Mediterranean diet score and the DASH diet score, not taking the food items on the FFQ available in the Memory and Aging Project (MAP) into account. For example, MAP only had strawberries available to represent berries [15]. The MIND diet score comprises 15 food items, including 10 favorable items: green leafy vegetables, other vegetables, berries, nuts, whole grains, olive oil, beans, fish, poultry, and wine; and 5 non-favorable items: butter/margarine, cheese, red meat/ meat products, fast food/fried food, and pastry/sweets [16]. Population-specific foods were added to these categories (e.g., sauerkraut: fermented cabbage). Supplementary Table 3 presents the foods and cut-offs per food group. Olive oil consumption was scored 1 if used as the primary oil and 0 otherwise, according to the published MIND diet guideline. All other food groups were scored $0,0.5$ or 1 according to the frequency of consumption of each food item portion and/or when the intake of the food item adhered to the MIND diet score. Scores on all food groups were summed to calculate the total MIND score, ranging from 0 to 15, with 15 indicating highest adherence to the MIND diet guideline.

\section{Data-derived dietary patterns}

To derive data-driven dietary patterns, food variables were first grouped based on food groups (e.g., berries) as done previously with this FFQ [37], resulting in 39 food groups (see Supplementary Table 1 for details). Second, principle component analysis (PCA) was used to identify data-derived dietary patterns based on these 39 food groups. Assumptions for using this method were checked and met [38]. Specifically, we performed a PCA based on Spearman correlation (ranking of all individuals per food group). Factor loadings were calculated after Varimax rotation [39], to obtain components that are uncorrelated and, therefore, better interpretable. Factors were extracted based on Eigenvalues greater than 1.5 shown in the scree plot, based on experience that a lower cut-off would introduce uninterpretable a posteriori patterns.

\section{Covariates}

Data on height and weight were used to calculate BMI $(\mathrm{kg} /$ $\mathrm{m}^{2}$ ). Items of the PASE Questionnaire [40] were used as a proxy for physical activity, as we calculated the number of active days during the last week (e.g., walking, leisure activities, sports and household activities). Smoking status was divided into three categories: never smoked, former smoker and current smoker. Apolipoprotein E4 (APOE4)-status was included as a dichotomous variable (carrier vs non-carrier). To account for potential attrition bias, multiple imputation was used to create ten different copies of the original dataset and to replace missing values with imputed values. Imputed values were calculated from their predictive distribution based on the observed data [41]. Consequently, to account for uncertainty, results of the created datasets $(n=10)$ were combined and pooled in a pooled dataset (Supplementary table 4). Data that were imputed: education in years: $n=1$ (0.3\%); height: $n=2(0.5 \%)$; weight: $n=4(1.0 \%)$; physical activity score: $n=7(1.8 \%)$ and smoking status: $n=2(0.5 \%)$.

\section{Statistical analyses}

Descriptive statistics were presented as mean (SD), median (interquartile range), or n (\%) where appropriate. We used linear regression analyses to investigate the association between dietary patterns and cognition. First, analyses were adjusted for age, sex and education (Model 1). Then analyses were additionally adjusted for total daily energy intake (kcal), BMI, smoking status and physical activity and APOE4-status (Model 2). Model 2 was considered the fully adjusted model for the Mediterranean and MIND diet analyses. When analyzing the data-derived patterns, an additional Model 3 included all data-derived patterns simultaneously into the model in addition to Model 2 covariates. We used model 3 to assess the independent association of dataderived patterns with the outcomes and, therefore, considered Model 3 the fully adjusted model for these patterns. The fully adjusted models (Mediterranean diet + MIND: model 2, PCA: model 3) were also run after exclusion of MCI subjects to rule out that effects would be mainly driven, or rather obscured, by subjects with clinically significant cognitive impairment. Data are represented as unstandardized betas and $95 \%$ confidence intervals. A $p$ value was considered significant when $<0.05$. Analyses were conducted using SPSS version 22 [42].

\section{Results}

Participants were on average $69.4 \pm 5.6$ years old, included $202(52 \%)$ females, had a MMSE score of $29.1 \pm 1.2$ and had completed 14 (median; IQR 12-17) years of education. Descriptive statistics are listed in Table 1. The average Mediterranean diet score was $4.5 \pm 1.9(\max .9)$ and the average MIND diet score was $6.4 \pm 1.4$ (max. 15). MD and MIND scores were moderately correlated $(r=0.37)$ and did not differ between subgroups (SCD, REL, MCI, CON).

First, associations of cognition with the Mediterranean and MIND diet scores were investigated (Table 2). Using model 1, we found associations between higher 
Table 1 Demographics

\begin{tabular}{ll}
\hline Demographic & $N=389$ \\
\hline Age (years) & $69.4 \pm 5.6$ \\
Sex female $n(\%)$ & $202(51.9)$ \\
Education (years) $^{\mathrm{b}}$ & $14.0(\mathrm{IQR}: 12.0-17.0)$ \\
${\text { ApoE4-carrier } n(\%)^{\mathrm{a}}}^{2}$ & $107(27.9)$ \\
BMI $\left(\mathrm{kg} / \mathrm{m}^{2}\right)$ & $25.9 \pm 3.7$ \\
Smoking status $n(\%)^{\mathrm{b}}$ & \\
Never smoked & $192(49.4)$ \\
Former smokers & $165(42.4)$ \\
Current smokers & $32(8.2)$ \\
Physical activity score & $358.4 \pm 142.4$ \\
Total daily energy intake (kcal/day) & $2315.4 \pm 746.5$ \\
Cognitive status $n(\%)$ & \\
Cognitively normal & $329(85)$ \\
MCI & $60(15)$ \\
MMSE total score, max. 30 & $29.1 \pm 1.2$ \\
Mediterranean diet, max. 9 & $4.5 \pm 1.9$ \\
MIND diet, max. 15 & $6.4 \pm 1.4$ \\
\hline
\end{tabular}

This table presents the demographics of the total study population. For continuous variables, mean and standard deviations are given, or median and interquartile range (IQR) if data were not normally distributed; for categorical variables, numbers and percentages are given. BMI: body mass index

$M C I$ mild cognitive impairment, MMSE mini mental state examination

aPOEe4-status: $n=383$, missing $n=6(1.5 \%)$

${ }^{\mathrm{b}}$ Imputed data: education $n=1(0.3 \%)$; physical activity score: $n=7$ (1.8\%); smoking status: $n=2(0.5 \%)$

Mediterranean diet score and better memory $(p=0.003)$ and language $(p=0.017)$. In addition, higher MIND diet score was associated with better memory $(p=0.046)$. In the fully adjusted model, the associations of greater adherence to both the Mediterranean and MIND diet with better memory remained ( $p=0.004$ and $p=0.029$, respectively), whereas the associations with language fell short of significance (Mediterranean $p=0.051$, MIND $p=0.053$ ). After the exclusion of subjects with MCI, associations of higher Mediterranean and MIND diet score with language became significant (Model 2: $p=0.031$ and $p=0.027$, respectively), while the association between MIND and memory was lost $(p=0.290)$.

Subsequently, with the use of PCA, we identified six data-derived dietary patterns, explaining $44 \%$ of the variance. We named the dietary patterns (1) 'Warm meal', (2) 'Vegetables', (3) 'Cereals and nuts', (4) 'Alcoholic beverages', (5) 'Bread meal' and 6) 'Snacks' based on the highest intake of the dietary pattern contents (Supplementary table 5: loading of food groups on PCA factors).
Groups did not differ regarding these patterns, except that subjects with MCI had lower scores for the 'Alcoholic beverages' component.

Table 3 presents the associations of the PCA-based dietary patterns with the cognitive domains. Higher 'Alcoholic beverages' dietary pattern score was associated with higher scores on all domains except for visuospatial functioning in all models. Specifically, we found that a higher 'Alcoholic beverages' dietary pattern score was related to better memory $(p=0.001)$, language ( $p=0.001)$, executive functioning $(p=0.001)$ and working memory $(p<0.001)$. In addition, higher 'Cereals and Nuts' dietary pattern score was associated with better language $(p=0.041)$, but only in the fully adjusted model (Model 3). Using model 1, we found an association between higher adherence to the 'Vegetables' pattern and better memory $(p=0.039)$, which lost significance in models $2(p=0.059)$ and $3(p=0.080)$.

After the exclusion of subjects with MCI, analyses were repeated using the fully adjusted model (Model 3). Higher adherence to the 'Alcoholic beverages' dietary pattern remained associated with better memory $(p=0.009)$, language $(p=0.045)$ and working memory $(p=0.012)$. The association with executive functions, however, attenuated and became non-significant $(p=0.060)$. Also, the association between the 'Cereals and Nuts' dietary pattern and better language attenuated in the cognitive unimpaired and became non-significant $(p=0.055)$. However, we did find an association between higher adherence to the "Cereals and Nuts' dietary pattern and better memory $(p=0.042)$ in the cognitively normals.

\section{Discussion}

In this study, we found that higher adherence to the Mediterranean diet or the MIND diet was associated with aspects of cognition in an elderly sample free of dementia, enriched with individuals at increased risk for AD. More specifically, higher adherence to MD and MIND was associated with better memory, and exclusion of MCI subjects revealed that Mediterranean and MIND diet were related to language in the unimpaired group. In addition, an empirical dietary pattern mainly characterized by intake of alcohol was associated with several cognitive domain scores. Although exclusion of MCI subjects attenuated the associations with this component, most remained significant.

These results are in line with population-based studies, which observed a positive association between adherence to the Mediterranean diet [43-46], or MIND diet and cognitive decline or dementia $[15,16,18,20]$. While not all cross-sectional [21, 22] and longitudinal [47-49] studies did replicate these findings, a meta-analysis on the Mediterranean diet and a systematic review of the MIND diet 
Table 2 Mediterranean and MIND diet scores on cognitive outcomes

\begin{tabular}{|c|c|c|c|}
\hline Domain & Group & Mediterranean diet & MIND diet \\
\hline \multicolumn{4}{|l|}{ Memory } \\
\hline Model 1 & Total & $0.051[0.048 \text { to } 0.053]^{*}$ & $0.042[0.001 \text { to } 0.082]^{*}$ \\
\hline Model 2 & Total & $0.049[0.014 \text { to } 0.085]^{*}$ & $0.045[0.003 \text { to } 0.087]^{*}$ \\
\hline Model 2 & $\mathrm{CN}$ & $0.037[0.009 \text { to } 0.064]^{*}$ & $0.019[-0.014$ to 0.051$]$ \\
\hline \multicolumn{4}{|l|}{ Language } \\
\hline Model 1 & Total & $0.040[0.023 \text { to } 0.057]^{*}$ & $0.036[-0.003$ to 0.076$]$ \\
\hline Model 2 & Total & $0.033[-0.002$ to 0.067$]$ & $0.039[-0.002$ to 0.079$]$ \\
\hline Model 2 & $\mathrm{CN}$ & $0.030[0.003 \text { to } 0.058]^{*}$ & 0.037 [0.004 to 0.069$]^{*}$ \\
\hline \multicolumn{4}{|c|}{ Executive functioning } \\
\hline Model 1 & Total & $0.018[0.001$ to 0.036$]$ & $0.013[-0.028$ to 0.055$]$ \\
\hline Model 2 & Total & $0.013[-0.023$ to 0.050$]$ & $0.014[-0.029$ to 0.057$]$ \\
\hline Model 2 & $\mathrm{CN}$ & $0.014[-0.016$ to 0.044$]$ & $0.014[-0.022$ to 0.049$]$ \\
\hline \multicolumn{4}{|c|}{ Working memory } \\
\hline Model 1 & Total & $0.025[0.006$ to 0.043$]$ & $.028[-0.014$ to 0.070$]$ \\
\hline Model 2 & Total & $0.022[-0.017$ to 0.060$]$ & $.031[-0.014$ to 0.076$]$ \\
\hline Model 2 & $\mathrm{CN}$ & $0.025[-0.011$ to 0.060$]$ & $.031[-0.011$ to 0.073$]$ \\
\hline \multicolumn{4}{|c|}{ Visuospatial functioning } \\
\hline Model 1 & Total & $0.002[-0.014$ to 0.017$]$ & $.014[-0.021$ to 0.049$]$ \\
\hline Model 2 & Total & $-0.010[-0.042$ to 0.022$]$ & $.014[-0.024$ to 0.052$]$ \\
\hline Model 2 & $\mathrm{CN}$ & $-0.006[-0.035$ to 0.023$]$ & $.026[-0.008$ to 0.059$]$ \\
\hline
\end{tabular}

Presented are the unstandardized B and [95\% CI's]. Model 1: adjusted for age, sex and education $(n=389)$ Model 2: adjusted for age, sex, education, APOe4-status, total daily energy intake ( $\mathrm{kcal}), \mathrm{BMI}\left(\mathrm{kg} / \mathrm{m}^{2}\right)$, smoking status and physical activity $(n=383) . * p<0.05$. CN: cognitively normal (excluding MCI, $n=323$ ) support that greater adherence to these diets are positively associated with cognitive functioning, cognitive decline and $\mathrm{AD}[13,50,51]$. Extending the evidence from these population-based studies, we here show that higher adherence to the Mediterranean diet and MIND diet are also associated with cognitive outcomes in a sample enriched with subjects who are either clinically or genetically at increased risk for $\mathrm{AD}$.

The associations between the dietary patterns and cognition were most pronounced for memory and language. This has also been observed in some other studies [52, 53] and may be mediated by dietary effects on mediotemporal atrophy [53] or on cerebral amyloid pathology [54], which first affects memory function. Our language tasks assessed mainly verbal fluency performance. Verbal fluency was shown to be affected in individuals with amnestic MCI and cognitive complaints (e.g., [55]) and it relies on storage and retrieval of verbal information from semantic memory. As our sample was enriched for AD risk, and memory and language are affected early in the course of $\mathrm{AD}$, it is tempting to speculate that the apparent specificity of the diet-cognition associations which we observed stems from protective effects of MEDI and MIND diets which mitigate early cognitive effects of AD. This hypothesis will need to be examined with biomarker data in DELCODE and other deeply phenotyped samples.
Regarding confounders, it is not likely that the associations that were found were driven by cardiovascular risk factors, because further adjustment for these diseases (data not shown) did not change the betas of the associations. After exclusion of individuals with cognitive impairment, some associations attenuated in significance or effect size. Analyses in larger samples are needed to investigate whether these changes indeed indicate different associations in different subgroups, or whether they were due to statistical power loss.

Longitudinal and imaging analyses in DELCODE will allow us to address sub-group analysis as well as the biological correlates of different dietary patterns.

A methodological issue with predefined dietary patterns is that they may not well represent the typical diet in many countries. We, therefore, supplemented the analysis with a data-driven approach. Two of the six data-derived dietary patterns also revealed a positive association with better cognition, PCA pattern 4 'Alcoholic beverages' (being related to with better functioning in several domains), and PCA pattern 3 'Cereals and Nuts' (being related to language in the total group and with memory in the cognitively normal group).

Our findings with respect to alcohol intake suggest a possibly beneficial effect of mild to moderate alcohol consumption for cognition, as has been described before in longitudinal studies [56-59]. Whereas light to moderate alcohol 
Table 3 Data-derived dietary patterns and cognitive outcomes

\begin{tabular}{|c|c|c|c|c|c|c|c|c|}
\hline Domain & Model & Group & Warm meal & Vegetables & Cereals and nuts & $\begin{array}{l}\text { Alcoholic bever- } \\
\text { ages }\end{array}$ & Bread meal & Snacks \\
\hline \multirow[t]{4}{*}{ Memory } & Model 1 & Total & $\begin{array}{l}-0.023[-0.081 \\
\text { to } 0.036]\end{array}$ & $\begin{array}{l}0.060[0.003 \text { to } \\
0.118]^{*}\end{array}$ & $\begin{array}{l}0.024[-0.036 \text { to } \\
0.084]\end{array}$ & $\begin{array}{l}0.095[0.034 \text { to } \\
0.156]^{*}\end{array}$ & $\begin{array}{l}-0.009[-0.067 \\
\text { to } 0.048]\end{array}$ & $\begin{array}{l}0.015[-0.043 \text { to } \\
0.074]\end{array}$ \\
\hline & Model 2 & Total & $\begin{array}{l}-0.029[-0.094 \\
\text { to } 0.035]\end{array}$ & $\begin{array}{l}0.058[-0.002 \text { to } \\
0.119]\end{array}$ & $\begin{array}{l}00.035[-0.028 \\
\text { to } 0.097]\end{array}$ & $\begin{array}{l}0.093[0.031 \text { to } \\
0.154]^{*}\end{array}$ & $\begin{array}{l}-0.020[-0.084 \\
\text { to } 0.045]\end{array}$ & $\begin{array}{l}0.004[-0.062 \text { to } \\
0.071]\end{array}$ \\
\hline & Model 3 & Total & $\begin{array}{l}0.021[-0.057 \text { to } \\
0.098]\end{array}$ & $\begin{array}{l}0.057[-0.007 \text { to } \\
0.121]\end{array}$ & $\begin{array}{l}0.061[-0.005 \text { to } \\
0.127]\end{array}$ & $\begin{array}{l}0.108[0.042 \text { to } \\
0.175]^{*}\end{array}$ & $\begin{array}{l}.000[-0.035 \text { to } \\
0.036]\end{array}$ & $\begin{array}{l}0.046[-0.033 \text { to } \\
0.125]\end{array}$ \\
\hline & Model 3 & $\mathrm{CN}$ & $\begin{array}{l}0.047[-0.013 \text { to } \\
0.107]\end{array}$ & $\begin{array}{l}0.045[-0.005 \text { to } \\
0.096]\end{array}$ & $\begin{array}{l}0.055[.002 \text { to } \\
0.109]^{*}\end{array}$ & $\begin{array}{l}0.071[0.018 \text { to } \\
0.124]^{*}\end{array}$ & $\begin{array}{l}.044[-0.009 \text { to } \\
0.098]\end{array}$ & $\begin{array}{l}.051[-0.011 \text { to } \\
0.114]\end{array}$ \\
\hline \multirow[t]{4}{*}{ Language } & Model 1 & Total & $\begin{array}{l}-0.016[-0.072 \\
\text { to } 0.040]\end{array}$ & $\begin{array}{l}0.052[-0.003 \text { to } \\
0.108]\end{array}$ & $\begin{array}{l}0.051[-0.007 \text { to } \\
0.109]\end{array}$ & $\begin{array}{l}0.104[0.046 \text { to } \\
0.162]^{*}\end{array}$ & $\begin{array}{l}.019[-0.037 \text { to } \\
0.074]\end{array}$ & $\begin{array}{l}-0.003[-0.060 \text { to } \\
0.053]\end{array}$ \\
\hline & Model 2 & Total & $\begin{array}{l}-0.027[-0.090 \\
\text { to } 0.035]\end{array}$ & $\begin{array}{l}0.040[-0.019 \text { to } \\
0.098]\end{array}$ & $\begin{array}{l}0.046[-0.014 \text { to } \\
0.106]\end{array}$ & $\begin{array}{l}0.099[0.040 \text { to } \\
0.158]^{*}\end{array}$ & $\begin{array}{l}0.002[-0.060 \text { to } \\
0.064]\end{array}$ & $\begin{array}{l}-0.029[-0.093 \text { to } \\
0.035]\end{array}$ \\
\hline & Model 3 & Total & $\begin{array}{l}0.010[-0.064 \text { to } \\
0.085]\end{array}$ & $\begin{array}{l}0.035[-0.027 \text { to } \\
0.096]\end{array}$ & $\begin{array}{l}00.067[0.003 \text { to } \\
0.131]^{*}\end{array}$ & $\begin{array}{l}0.110[0.046 \text { to } \\
0.174]^{*}\end{array}$ & $\begin{array}{l}.010[-0.057 \text { to } \\
0.077]\end{array}$ & $\begin{array}{l}0.009[-0.068 \text { to } \\
0.085]\end{array}$ \\
\hline & Model 3 & $\mathrm{CN}$ & $\begin{array}{l}-0.005[-0.065 \\
\text { to } 0.055]\end{array}$ & $\begin{array}{l}.044[-0.006 \text { to } \\
0.094]\end{array}$ & $\begin{array}{l}0.052[-0.001 \text { to } \\
0.105]\end{array}$ & $\begin{array}{l}0.054[0.001 \text { to } \\
0.107]^{*}\end{array}$ & $\begin{array}{l}.044[-0.009 \text { to } \\
0.097]\end{array}$ & $\begin{array}{l}0.002[-0.060 \text { to } \\
0.065]\end{array}$ \\
\hline \multirow[t]{4}{*}{ Exec. function } & Model 1 & Total & $\begin{array}{l}-0.016[-0.075 \\
\text { to } 0.043]\end{array}$ & $\begin{array}{l}0.021[-0.037 \text { to } \\
0.080]\end{array}$ & $\begin{array}{l}0.027[-0.034 \text { to } \\
0.088]\end{array}$ & $\begin{array}{l}0.102[0.041 \text { to } \\
0.163]^{*}\end{array}$ & $\begin{array}{l}-0.001[-0.058 \\
\text { to } 0.057]\end{array}$ & $\begin{array}{l}-0.007[-0.066 \text { to } \\
0.052]\end{array}$ \\
\hline & Model 2 & Total & $\begin{array}{l}-0.024[-0.090 \\
\text { to } 0.043]\end{array}$ & $\begin{array}{l}0.010[-0.052 \text { to } \\
0.072]\end{array}$ & $\begin{array}{l}0.029[-0.035 \text { to } \\
0.093]\end{array}$ & $\begin{array}{l}0.104[0.042 \text { to } \\
0.167]^{*}\end{array}$ & $\begin{array}{l}-0.016[-0.082 \\
\text { to } 0.050]\end{array}$ & $\begin{array}{l}-0.022[-0.089 \text { to } \\
0.046]\end{array}$ \\
\hline & Model 3 & Total & $\begin{array}{l}0.000[-0.079 \text { to } \\
0.079]\end{array}$ & $\begin{array}{l}-0.003[-0.068 \\
\text { to } 0.063]\end{array}$ & $\begin{array}{l}0.048[-0.020 \text { to } \\
0.116]\end{array}$ & $\begin{array}{l}0.113[0.045 \text { to } \\
0.181]^{*}\end{array}$ & $\begin{array}{l}-0.020[-0.092 \\
\text { to } 0.051]\end{array}$ & $\begin{array}{l}-0.001[-0.082 \text { to } \\
0.080]\end{array}$ \\
\hline & Model 3 & $\mathrm{CN}$ & $\begin{array}{l}-0.011[-0.077 \\
\text { to } 0.001]\end{array}$ & $\begin{array}{l}0.021[-0.077 \text { to } \\
0.056]\end{array}$ & $\begin{array}{l}0.031[-0.028 \text { to } \\
0.090]\end{array}$ & $\begin{array}{l}0.056[-0.002 \text { to } \\
0.115]\end{array}$ & $\begin{array}{l}.027[-0.032 \text { to } \\
0.086]\end{array}$ & $\begin{array}{l}0.009[-0.060 \text { to } \\
0.077]\end{array}$ \\
\hline \multirow[t]{4}{*}{ Working mem } & Model 1 & Total & $\begin{array}{l}-0.037[-0.099 \\
\text { to } 0.025]\end{array}$ & $\begin{array}{l}0.018[-0.043 \text { to } \\
0.079]\end{array}$ & $\begin{array}{l}0.052[-0.012 \text { to } \\
0.116]\end{array}$ & $\begin{array}{l}0.122[0.058 \text { to } \\
0.185]^{*}\end{array}$ & $\begin{array}{l}-0.010[-0.071 \\
\text { to } 0.051]\end{array}$ & $\begin{array}{l}-0.007[-0.070 \text { to } \\
0.055]\end{array}$ \\
\hline & Model 2 & Total & $\begin{array}{l}-0.045[-0.114 \\
\text { to } 0.025]\end{array}$ & $\begin{array}{l}0.005[-0.060 \text { to } \\
0.070]\end{array}$ & $\begin{array}{l}0.048[-0.019 \text { to } \\
0.115]\end{array}$ & $\begin{array}{l}0.122[0.056 \text { to } \\
0.187]^{*}\end{array}$ & $\begin{array}{l}-0.023[-0.092 \\
\text { to } 0.046]\end{array}$ & $\begin{array}{l}-0.019[-0.090 \text { to } \\
0.052]\end{array}$ \\
\hline & Model 3 & Total & $\begin{array}{l}-0.019[-0.100 \\
\text { to } 0.063]\end{array}$ & $\begin{array}{l}-0.014[-0.083 \\
\text { to } 0.054]\end{array}$ & $\begin{array}{l}0.067[-0.004 \text { to } \\
0.138]\end{array}$ & $\begin{array}{l}0.132[0.061 \text { to } \\
0.202]^{*}\end{array}$ & $\begin{array}{l}-0.034[-0.108 \\
\text { to } 0.041]\end{array}$ & $\begin{array}{l}-0.003[-0.087 \text { to } \\
0.081]\end{array}$ \\
\hline & Model 3 & $\mathrm{CN}$ & $\begin{array}{l}-0.035[-0.112 \\
\text { to } 0.043]\end{array}$ & $\begin{array}{l}0.008[-0.057 \text { to } \\
0.073]\end{array}$ & $\begin{array}{l}0.067[-0.001 \text { to } \\
0.136]\end{array}$ & $\begin{array}{l}0.088[0.019 \text { to } \\
0.156]^{*}\end{array}$ & $\begin{array}{l}.011[-0.058 \text { to } \\
0.080]\end{array}$ & $\begin{array}{l}.009[-0.071 \text { to } \\
0.088]\end{array}$ \\
\hline \multirow[t]{4}{*}{ Visuosp. Func } & Model 1 & Total & $\begin{array}{l}0.023[-0.029 \text { to } \\
0.075]\end{array}$ & $\begin{array}{l}0.024[-0.027 \text { to } \\
0.075]\end{array}$ & $\begin{array}{l}0.033[-0.021 \text { to } \\
0.087]\end{array}$ & $\begin{array}{l}00.024[-0.031 \text { to } \\
0.078]\end{array}$ & $\begin{array}{l}-0.009[-0.060 \\
\text { to } 0.042]\end{array}$ & $\begin{array}{l}.004[-0.049 \text { to } \\
0.056]\end{array}$ \\
\hline & Model 2 & Total & $\begin{array}{l}0.015[-0.043 \text { to } \\
0.073]\end{array}$ & $\begin{array}{l}0.009[-0.045 \text { to } \\
0.063]\end{array}$ & $\begin{array}{l}0.029[-0.027 \text { to } \\
0.085]\end{array}$ & $\begin{array}{l}0.023[-0.032 \text { to } \\
0.079]\end{array}$ & $\begin{array}{l}-0.044[-0.102 \\
\text { to } 0.013]\end{array}$ & $\begin{array}{l}-0.021[-0.080 \text { to } \\
0.038]\end{array}$ \\
\hline & Model 3 & Total & $\begin{array}{l}0.012[-0.058 \text { to } \\
0.082]\end{array}$ & $\begin{array}{l}-0.003[-0.061 \\
\text { to } 0.054]\end{array}$ & $\begin{array}{l}0.032[-0.028 \text { to } \\
0.092]\end{array}$ & $\begin{array}{l}0.031[-0.029 \text { to } \\
0.091]\end{array}$ & $\begin{array}{l}-0.046[-0.109 \\
\text { to } 0.017]\end{array}$ & $\begin{array}{l}-0.015[-0.087 \text { to } \\
0.057]\end{array}$ \\
\hline & Model 3 & $\mathrm{CN}$ & $\begin{array}{l}0.000[-0.062 \text { to } \\
0.062]\end{array}$ & $\begin{array}{l}0.009[-0.043 \text { to } \\
0.062]\end{array}$ & $\begin{array}{l}0.029[-0.026 \text { to } \\
0.84]\end{array}$ & $\begin{array}{l}-0.001[-0.056 \\
\text { to } 0.054]\end{array}$ & $\begin{array}{l}-0.020[-0.076 \\
\text { to } 0.035]\end{array}$ & $\begin{array}{l}-0.012[-0.015 \text { to } \\
0.010]\end{array}$ \\
\hline
\end{tabular}

Presented are the results of the linear regression models between the PCA factors and cognitive outcomes. Reported are the unstandardized $\mathrm{B}$ and [95\% CI's]. Model 1: adjusted for age, sex and education $(n=389)$. Model 2: adjusted for age, sex, education, total daily energy intake (kcal), BMI $(\mathrm{kg} / \mathrm{m} 3)$, smoking status, physical activity and APOe4-status $(n=383)$. Model 3: model 2 with all PCA factors entered simultaneously. ${ }^{*} p<0.05$. CN: cognitively normal, $N=323$

consumption might be beneficial for cognitive health, high alcohol intake or abuse of alcohol has been shown to be detrimental for brain function due to a U-shaped dose-response relationship [60,61]. The majority of our sample had a moderate ethanol intake (total group mean $18.8 \pm 24.4 \mathrm{~g} /$ day) which is in accordance with the alcohol guidelines of the Mediterranean diet ( $84 \%$ of females $<25 \mathrm{~g} /$ day, $88 \%$ of males $<50 \mathrm{~g} /$ day). Subjects with MCI had lower scores for PCA component 4 , but the total amount of alcohol intake per day was not different, suggesting that all components of PCA4 contribute to the observed association and not solely the total alcohol intake. To rule out reversed causation, we excluded MCI patients and nearly all associations remained significant after exclusion. Thus, subjects worried about their memory for good reasons (i.e., subjects with MCI) may reduce their alcohol intake, but the observed associations between the "alcoholic beverages" component and cognition unlikely result from this change. It would be interesting for future studies to look into foods that often accompany alcohol intake, such as fish meals, that might also contribute to the observed positive association. Fruit was negatively loading on the 'alcoholic beverages' pattern. However, additional 
adjusting for fruit intake did not change the associations (data not shown).

Regarding the cereals and nuts, and bread meal pattern, we have found inconsistent results. Wholegrain and nuts are included in the Mediterranean diet and MIND guidelines, because their potential beneficial health effects can primarily be ascribed to fiber and phytonutrients $[62,63]$. However, the inconsistent findings of the present study are in line with previous studies that did not find a relationship between wholegrain and cognitive function or decline [64, 65]. Results from studies that investigated nuts in relation to both outcomes have been mixed, as some found associations, while others did not [48, 66-68].

The primary strength of this study involved the study population, as the study was conducted in a sample of elderly that were free of dementia, enriched with individuals at increased risk for AD. Results from the present study are a significant addition to the current literature, which is mainly based on population-based samples. Second, we used an extensive neuropsychological test battery to assess cognitive functioning, which is more sensitive to differences compared to measures of global cognitive functioning such as the MMSE. Third, we used a state-of-the-art psychometrics method to aggregate neuropsychological scores into cognitive domains scores. Fourth, we used a detailed food frequency questionnaire, providing information on the amount and frequency of nutrient and food intake, which was modified specifically for a German population, which enabled us to use a combination of both predefined and data-derived dietary patterns to assess adherence to dietary patterns in this study population.

This study has several limitations. The cross-sectional study design precludes conclusions about temporality of associations or causality. Longitudinal data will become available in DELCODE and will be used to study whether diet is associated with future cognitive decline. The analyzed sample consists of several subgroups, which we analyzed together as they did not differ regarding diet and-with the exception of MCI patients-performed within normal limits at neuropsychological testing. Individuals with amnestic MCI might have had difficulties in filling out the FFQ. However, all study participants had a study partner (e.g., spouse) to assist and we excluded questionnaires indicating an unrealistic nutritional intake. It has also been reported that FFQs from MCI patients are valid if a study partner is involved [69]. We used a FFQ, which is subject to measurement error. To account for potential systematic measurement error, we adjusted the relationships under study for total energy intake [70]. However, we acknowledge the possible presence of non-differential misclassification, which may have led to bias towards the null [71]. Furthermore, while the subjects with SCD and with an AD relative may be at increased risk for having preclinical $\mathrm{AD}$, they are generally healthy elderly research participants similar to those in the volunteer control group. Subgroup analyses (e.g., in subjects with Amyloid pathology) are planned once the complete sample and biomarker data will be available. All participants were German and mainly well educated, white individuals, limiting the generalizability of the findings to other countries or cultures. While our sample is heterogeneous in terms of recruitment, it represents a group of elderly which is enriched for ADrisk, but free of dementia. Importantly, our results align well with data from general population studies, suggesting that the association of diet with specific cognitive functions also holds true in risk-enriched populations, which is a prerequisite for considering nutritional intervention studies in such groups. As associations between diet and cognition are generally small, and the size of our sample was only moderate, we did not correct for multiple testing. While this limitation calls for a cautious interpretation, we note that the size and pattern of the associations found are consistent with much of the literature. Replication of our findings in other riskenriched cohorts, the study of imaging and fluid neurodegeneration biomarkers in relation to diet, and longitudinal studies are needed to corroborate the present results. The current results add to current literature on diet and cognition as a sample including individuals with increased risk for AD was studied and an elaborate cognitive assessment has been used to construct sensitive cognitive outcome measures.

In this sample of German elderly free of dementia, Mediterranean diet and MIND diet were related to better memory and language, and two data-derived dietary patterns, one characterized by high intake of cereals and nuts and the other one by higher intake of alcoholic beverages were also related to better cognition.

The present study results would be consistent with a beneficial effect of some diets and dietary components on cognitive health. We consider it encouraging that associations previously found in population samples were also evident in our risk-enriched sample, which can be conceived as a target sample for prevention of cognitive decline, as subjects often are concerned about their cognitive health and motivated to change their lifestyle. It may not be "too late" for dietary changes to be effective in such populations.

In sum, the current results suggest that dietary intake is of importance in individuals free of dementia, ranging from cognitively healthy to MCI, and should be taken into account when designing interventions to delay cognitive decline.

Acknowledgements We would like to thank all the participants for their contribution to this study. We kindly thank Ulrich Harttig, Sabine Grams and Ellen Kohlsdorf from the DIfE in Potsdam, Germany, for hosting the EPIC-FFQ data base and for their support with the data of this study.

Funding This project has been funded by the DZNE and by the Diet Body Brain research cluster funded by the German Federal Ministry of 
Education and Research (BMBF; grant 01EA1809C). LW received an International Research Grant from the Alzheimer Forschung Initiative e.V. SS is a recipient of a research grant from the EU Joint ProgrammeNeurodegenerative Disease Research (JPND_PS_FP-689-019; ZonMw Grant no. 733051043) and a research grant from Stichting Equilibrio. $\mathrm{WvdF}$ is recipient of a grant from NWO-FCB (NUDAD; project number 057-14-004).

\section{Compliance with ethical standards}

Conflict of interest On behalf of all authors, the corresponding author states that there is no conflict of interest.

Open Access This article is licensed under a Creative Commons Attribution 4.0 International License, which permits use, sharing, adaptation, distribution and reproduction in any medium or format, as long as you give appropriate credit to the original author(s) and the source, provide a link to the Creative Commons licence, and indicate if changes were made. The images or other third party material in this article are included in the article's Creative Commons licence, unless indicated otherwise in a credit line to the material. If material is not included in the article's Creative Commons licence and your intended use is not permitted by statutory regulation or exceeds the permitted use, you will need to obtain permission directly from the copyright holder. To view a copy of this licence, visit http://creativecommons.org/licenses/by/4.0/.

\section{References}

1. Prince M, Ali GC, Guerchet M, Prina AM, Albanese E, Wu YT (2016) Recent global trends in the prevalence and incidence of dementia, and survival with dementia. Alzheimers Res Ther 8(1):23. https://doi.org/10.1186/s13195-016-0188-8

2. Prince $M$, Wimo A, Guerchet $M$, Ali GC, Wu YT, Prina M, International AsD (2015) World Alzheimer Report 2015. In: The Global Impact of Dementia: An analysis of prevalence, incidence, cost and trends. World Alzheimer Report. Alzheimer's Disease International (ADI), London

3. Kivipelto M, Mangialasche F, Ngandu T (2018) Lifestyle interventions to prevent cognitive impairment, dementia and Alzheimer disease. Nat Rev Neurol 14(11):653-666. https://doi.org/10.1038/ s41582-018-0070-3

4. Scarmeas N, Anastasiou CA, Yannakoulia M (2018) Nutrition and prevention of cognitive impairment. Lancet Neurol 17(11):10061015. https://doi.org/10.1016/S1474-4422(18)30338-7

5. Solfrizzi V, Agosti P, Lozupone M, Custodero C, Schilardi A, Valiani V, Sardone R, Dibello V, Di Lena L, Lamanna A, Stallone R, Bellomo A, Greco A, Daniele A, Seripa D, Sabba C, Logroscino G, Panza F (2018) Nutritional intervention as a preventive approach for cognitive-related outcomes in cognitively healthy older adults: a systematic review. J Alzheimers Dis 64(s1):S229_ S254. https://doi.org/10.3233/JAD-179940

6. Hu N, Yu JT, Tan L, Wang YL, Sun L, Tan L (2013) Nutrition and the risk of Alzheimer's disease. Biomed Res Int 2013:524820. https://doi.org/10.1155/2013/524820

7. Solfrizzi V, Panza F, Frisardi V, Seripa D, Logroscino G, Imbimbo BP, Pilotto A (2011) Diet and Alzheimer's disease risk factors or prevention: the current evidence. Expert Rev Neurother 11(5):677-708. https://doi.org/10.1586/ern.11.56

8. Parletta N, Milte CM, Meyer BJ (2013) Nutritional modulation of cognitive function and mental health. J Nutr Biochem 24(5):725743. https://doi.org/10.1016/j.jnutbio.2013.01.002
9. Otaegui-Arrazola A, Amiano P, Elbusto A, Urdaneta E, MartinezLage P (2014) Diet, cognition, and Alzheimer's disease: food for thought. Eur J Nutr 53(1):1-23. https://doi.org/10.1007/s0039 4-013-0561-3

10. Cederholm T (2017) Fish consumption and omega-3 fatty acid supplementation for prevention or treatment of cognitive decline, dementia or Alzheimer's disease in older adults - any news? Curr Opin Clin Nutr Metab Care 20(2):104-109. https://doi. org/10.1097/mco.0000000000000350

11. Dominguez LJ, Barbagallo M (2018) Nutritional prevention of cognitive decline and dementia. Acta Biomed 89(2):276-290. https://doi.org/10.23750/abm.v89i2.7401

12. Solfrizzi V, Custodero C, Lozupone M, Imbimbo BP, Valiani V, Agosti P, Schilardi A, D'Introno A, La Montagna M, Calvani M, Guerra V, Sardone R, Abbrescia DI, Bellomo A, Greco A, Daniele A, Seripa D, Logroscino G, Sabba C, Panza F (2017) Relationships of dietary patterns, foods, and micro- and macronutrients with alzheimer's disease and late-life cognitive disorders: a systematic review. J Alzheimers Dis 59(3):815-849. https://doi. org/10.3233/JAD-170248

13. van den Brink AC, Brouwer-Brolsma EM, Berendsen AAM, van de Rest O (2019) The Mediterranean, dietary approaches to stop hypertension (DASH), and Mediterranean-DASH Intervention for neurodegenerative delay (MIND) diets are associated with less cognitive decline and a lower risk of alzheimer's disease-a review. Adv Nutr. https://doi.org/10.1093/advances/nmz054

14. Trichopoulou A, Kouris-Blazos A, Wahlqvist ML, Gnardellis C, Lagiou P, Polychronopoulos E, Vassilakou T, Lipworth L, Trichopoulos D (1995) Diet and overall survival in elderly people. BMJ (Clin Res Ed) 311(7018):1457-1460. https://doi.org/10.1136/ bmj.311.7018.1457

15. Morris MC, Tangney CC, Wang Y, Sacks FM, Barnes LL, Bennett DA, Aggarwal NT (2015) Mind diet slows cognitive decline with aging. Alzheimers Dement 11(9):1015-1022. https://doi. org/10.1016/j.jalz.2015.04.011

16. Morris MC, Tangney CC, Wang Y, Sacks FM, Bennett DA, Aggarwal NT (2015) MIND diet associated with reduced incidence of Alzheimer's disease. Alzheimers Dement 11(9):10071014. https://doi.org/10.1016/j.jalz.2014.11.009

17. McEvoy CT, Guyer H, Langa KM, Yaffe K (2017) Neuroprotective diets are associated with better cognitive function: the health and retirement study. J Am Geriatr Soc 65(8):1857-1862. https:// doi.org/10.1111/jgs.14922

18. Berendsen AM, Kang JH, Feskens EJM, de Groot C, Grodstein F, van de Rest O (2018) Association of long-term adherence to the MIND diet with cognitive function and cognitive decline in american women. J Nutr Health Aging 22(2):222-229. https://doi. org/10.1007/s12603-017-0909-0

19. Adjibade M, Assmann KE, Julia C, Galan P, Hercberg S, KesseGuyot E (2019) Prospective association between adherence to the MIND diet and subjective memory complaints in the French NutriNet-Sante cohort. J Neurol 266(4):942-952. https://doi. org/10.1007/s00415-019-09218-y

20. Hosking DE, Eramudugolla R, Cherbuin N, Anstey KJ (2019) MIND not Mediterranean diet related to 12 -year incidence of cognitive impairment in an Australian longitudinal cohort study. Alzheimers Dement 15(4):581-589. https://doi.org/10.1016/j. jalz.2018.12.011

21. Brouwer-Brolsma EM, Benati A, van de Wiel A, van Lee L, de Vries JHM, Feskens EJM, van de Rest O (2018) Higher Mediterranean Diet scores are not cross-sectionally associated with better cognitive scores in 20- to 70-year-old Dutch adults: the NQplus study. Nutr Res 59:80-89. https://doi.org/10.1016/j.nutre s.2018.07.013

22. Akbaraly TN, Singh-Manoux A, Dugravot A, Brunner EJ, Kivimaki M, Sabia S (2019) Association of midlife diet with 
subsequent risk for dementia. JAMA 321(10):957-968. https:// doi.org/10.1001/jama.2019.1432

23. Gardener H, Caunca MR (2018) Mediterranean diet in preventing neurodegenerative diseases. Curr Nutr Rep 7(1):10-20. https:// doi.org/10.1007/s13668-018-0222-5

24. Alles B, Samieri C, Feart C, Jutand MA, Laurin D, BarbergerGateau P (2012) Dietary patterns: a novel approach to examine the link between nutrition and cognitive function in older individuals. Nutr Res Rev 25(2):207-222. https://doi.org/10.1017/S095442241 2000133

25. Ozawa M, Ninomiya T, Ohara T, Doi Y, Uchida K, Shirota T, Yonemoto K, Kitazono T, Kiyohara Y (2013) Dietary patterns and risk of dementia in an elderly Japanese population: the Hisayama Study. Am J Clin Nutr 97(5):1076-1082. https://doi.org/10.3945/ ajcn.112.045575

26. Shakersain B, Santoni G, Larsson SC, Faxén-Irving G, Fastbom J, Fratiglioni L, Xu W (2016) Prudent diet may attenuate the adverse effects of Western diet on cognitive decline. Alzheimer's Dementia 12(2):100-109. https://doi.org/10.1016/j.jalz.2015.08.002

27. Gu Y, Nieves JW, Stern Y, Luchsinger JA, Scarmeas N (2010) Food combination and Alzheimer disease risk: a protective diet. Arch Neurol 67(6):699-706. https://doi.org/10.1001/archneurol .2010 .84

28. Jessen F, Amariglio RE, van Boxtel M, Breteler M, Ceccaldi M, Chetelat G, Dubois B, Dufouil C, Ellis KA, van der Flier WM, Glodzik L, van Harten AC, de Leon MJ, McHugh P, Mielke MM, Molinuevo JL, Mosconi L, Osorio RS, Perrotin A, Petersen RC, Rabin LA, Rami L, Reisberg B, Rentz DM, Sachdev PS, de la Sayette V, Saykin AJ, Scheltens P, Shulman MB, Slavin MJ, Sperling RA, Stewart R, Uspenskaya O, Vellas B, Visser PJ, Wagner M (2014) A conceptual framework for research on subjective cognitive decline in preclinical Alzheimer's disease. Alzheimers Dement 10(6):844-852. https://doi.org/10.1016/j.jalz.2014.01.001

29. Jessen F, Wolfsgruber S, Wiese B, Bickel H, Mosch E, Kaduszkiewicz H, Pentzek M, Riedel-Heller SG, Luck T, Fuchs A, Weyerer S, Werle J, van den Bussche H, Scherer M, Maier W, Wagner M (2014) AD dementia risk in late MCI, in early MCI, and in subjective memory impairment. Alzheimers Dement 10(1):76-83. https ://doi.org/10.1016/j.jalz.2012.09.017

30. Wesselman LMP, Doorduijn AS, de Leeuw FA, Verfaillie SCJ, van Leeuwenstijn-Koopman M, Slot RER, Kester MI, Prins ND, van de Rest O, de Schueren MAE, Scheltens P, Sikkes SAM, van der Flier WM (2019) Dietary patterns are related to clinical characteristics in memory clinic patients with subjective cognitive decline: the SCIENCe project. Nutrients 11:5. https://doi. org/10.3390/nu11051057

31. Jessen F, Spottke A, Boecker H, Brosseron F, Buerger K, Catak C, Fliessbach K, Franke C, Fuentes M, Heneka MT, Janowitz D, Kilimann I, Laske C, Menne F, Nestor P, Peters O, Priller J, Pross V, Ramirez A, Schneider A, Speck O, Spruth EJ, Teipel S, Vukovich R, Westerteicher C, Wiltfang J, Wolfsgruber S, Wagner M, Duzel E (2018) Design and first baseline data of the DZNE multicenter observational study on predementia Alzheimer's disease (DELCODE). Alzheimers Res Ther 10(1):15. https://doi. org/10.1186/s13195-017-0314-2

32. Wolfsgruber S, Kleineidam L, Guski J, Polcher A, Frommann I, Roeske S, Spruth EJ, Franke C, Priller J, Kilimann I, Teipel SJ, Buerger K, Janowitz D, Laske C, Buchmann M, Peters O, Menne F, Fuentes-Casan M, Wiltfang J, Bartels C, Duzel E, Metzger C, Glanz W, Thelen M, Spottke A, Ramirez A, Kofler B, Fließbach K, Schneider A, Heneka M, Brosseron F, Meiberth D, Jessen F, Wagner M (2020) Minor neuropsychological deficits in patients with subjective cognitive decline. Neurology (in press)

33. Noethlings U, Hoffmann K, Bergmann MM, Boeing H (2003) Portion size adds limited information on variance in food intake of participants in the EPIC-Potsdam study. J Nutr 133(2):510-515. https://doi.org/10.1093/jn/133.2.510

34. Nöthlings U, Hoffmann K, Bergmann MM, Boeing H (2007) Fitting portion sizes in a self-administered food frequency questionnaire. J Nutr 137(12):2781-2786. https://doi.org/10.1093/ jn/137.12.2781

35. Trichopoulou A, Costacou T, Bamia C, Trichopoulos D (2003) Adherence to a Mediterranean diet and survival in a Greek population. N Engl J Med 348(26):2599-2608. https://doi.org/10.1056/ NEJMoa025039

36. Galbete C, Schwingshackl L, Schwedhelm C, Boeing H, Schulze MB (2018) Evaluating Mediterranean diet and risk of chronic disease in cohort studies: an umbrella review of meta-analyses. Eur J Epidemiol 33(10):909-931. https://doi.org/10.1007/s1065 4-018-0427-3

37. Schwedhelm C, Iqbal K, Knüppel S, Schwingshackl L, Boeing H (2018) Contribution to the understanding of how principal component analysis-derived dietary patterns emerge from habitual data on food consumption. Am J Clin Nutr 107(2):227-235. https ://doi.org/10.1093/ajen/nqx027

38. Lever J, Krzywinski M, Altman N (2017) Principal component analysis. Nat Methods 14:641. https://doi.org/10.1038/nmeth.4346

39. Kaiser $H$ (1958) The varimax criterion for analytic rotation in factor analysis. Psychometrika 23(3):187-200

40. Washburn RA, Smith KW, Jette AM, Janney CA (1993) The physical activity scale for the elderly (PASE): development and evaluation. J Clin Epidemiol 46(2):153-162

41. Sterne JA, White IR, Carlin JB, Spratt M, Royston P, Kenward MG, Wood AM, Carpenter JR (2009) Multiple imputation for missing data in epidemiological and clinical research: potential and pitfalls. BMJ 338:b2393. https://doi.org/10.1136/bmj.b2393

42. IBM (2011) IBM SPSS statistics for windows, version 22.0 edn. IBM Corp, New York

43. Gardener S, Gu Y, Rainey-Smith SR, Keogh JB, Clifton PM, Mathieson SL, Taddei K, Mondal A, Ward VK, Scarmeas N, Barnes M, Ellis KA, Head R, Masters CL, Ames D, Macaulay SL, Rowe CC, Szoeke C, Martins RN, Group AR (2012) Adherence to a Mediterranean diet and Alzheimer's disease risk in an Australian population. Transl Psychiatry 2:e164. https://doi.org/10.1038/ tp.2012.91

44. Tangney CC, Li H, Wang Y, Barnes L, Schneider JA, Bennett DA, Morris MC (2014) Relation of DASH- and Mediterranean-like dietary patterns to cognitive decline in older persons. Neurology 83(16):1410-1416. https://doi.org/10.1212/wnl.0000000000 000884

45. Trichopoulou A, Kyrozis A, Rossi M, Katsoulis M, Trichopoulos D, La Vecchia C, Lagiou P (2015) Mediterranean diet and cognitive decline over time in an elderly Mediterranean population. Eur J Nutr 54(8):1311-1321. https://doi.org/10.1007/s0039 4-014-0811-Z

46. Galbete C, Toledo E, Toledo JB, Bes-Rastrollo M, Buil-Cosiales P, Marti A, Guillen-Grima F, Martinez-Gonzalez MA (2015) Mediterranean diet and cognitive function: the SUN project. J Nutr Health Aging 19(3):305-312. https://doi.org/10.1007/s1260 3-015-0441-z

47. Kesse-Guyot E, Andreeva VA, Lassale C, Ferry M, Jeandel C, Hercberg S, Galan P (2013) Mediterranean diet and cognitive function: a French study. Am J Clin Nutr 97(2):369-376. https:// doi.org/10.3945/ajen.112.047993

48. Samieri C, Grodstein F, Rosner BA, Kang JH, Cook NR, Manson JE, Buring JE, Willett WC, Okereke OI (2013) Mediterranean diet and cognitive function in older age. Epidemiology 24(4):490-499. https://doi.org/10.1097/EDE.0b013e318294a065

49. Psaltopoulou T, Kyrozis A, Stathopoulos P, Trichopoulos D, Vassilopoulos D, Trichopoulou A (2008) Diet, physical activity 
and cognitive impairment among elders: the EPIC-Greece cohort (European Prospective Investigation into Cancer and Nutrition). Public Health Nutr 11(10):1054-1062. https://doi.org/10.1017/ s1368980007001607

50. Gardener SL, Rainey-Smith SR (2018) The role of nutrition in cognitive function and brain ageing in the elderly. Curr Nutr Rep 7(3):139-149. https://doi.org/10.1007/s13668-018-0229-y

51. Chen X, Maguire B, Brodaty H, O'Leary F (2019) Dietary patterns and cognitive health in older adults: a systematic review. J Alzheimers Dis 67(2):583-619. https://doi.org/10.3233/JAD180468

52. Anastasiou CA, Yannakoulia M, Kosmidis MH, Dardiotis E, Hadjigeorgiou GM, Sakka P, Arampatzi X, Bougea A, Labropoulos I, Scarmeas N (2017) Mediterranean diet and cognitive health: Initial results from the Hellenic longitudinal investigation of ageing and diet. PLoS ONE 12(8):e0182048. https://doi.org/10.1371/ journal.pone. 0182048

53. Karstens AJ, Tussing-Humphreys L, Zhan L, Rajendran N, Cohen J, Dion C, Zhou XJ, Lamar M (2019) Associations of the Mediterranean diet with cognitive and neuroimaging phenotypes of dementia in healthy older adults. Am J Clin Nutr 109(2):361-368. https://doi.org/10.1093/ajen/nqy275

54. Matthews DC, Davies M, Murray J, Williams S, Tsui WH, Li Y, Andrews RD, Lukic A, McHugh P, Vallabhajosula S, de Leon MJ, Mosconi L (2014) Physical activity, mediterranean diet and biomarkers-assessed risk of alzheimer's: a multi-modality brain imaging study. Adv Mol imaging 4(4):43-57. https://doi. org/10.4236/ami.2014.44006

55. Nutter-Upham KE, Saykin AJ, Rabin LA, Roth RM, Wishart HA, Pare N, Flashman LA (2008) Verbal fluency performance in amnestic MCI and older adults with cognitive complaints. Arch Clin Neuropsychol 23(3):229-241. https://doi.org/10.1016/j. acn.2008.01.005

56. Fischer K, Melo van Lent D, Wolfsgruber S, Weinhold L, Kleineidam L, Bickel H, Scherer M, Eisele M, van den Bussche H, Wiese B, Konig HH, Weyerer S, Pentzek M, Rohr S, Maier W, Jessen F, Schmid M, Riedel-Heller SG, Wagner M (2018) Prospective associations between single foods, alzheimer's dementia and memory decline in the elderly. Nutrients 10(7):852. https:// doi.org/10.3390/nu10070852

57. Panza F, Frisardi V, Seripa D, Logroscino G, Santamato A, Imbimbo BP, Scafato E, Pilotto A, Solfrizzi V (2012) Alcohol consumption in mild cognitive impairment and dementia: harmful or neuroprotective? Int J Geriatr Psychiatry 27(12):1218-1238. https://doi.org/10.1002/gps.3772

58. Peters R, Peters J, Warner J, Beckett N, Bulpitt C (2008) Alcohol, dementia and cognitive decline in the elderly: a systematic review. Age Ageing 37(5):505-512. https://doi.org/10.1093/ageing/afn09

59. Weyerer S, Schaufele M, Wiese B, Maier W, Tebarth F, van den Bussche H, Pentzek M, Bickel H, Luppa M, Riedel-Heller SG (2011) Current alcohol consumption and its relationship to incident dementia: results from a 3-year follow-up study among primary care attenders aged 75 years and older. Age Ageing 40(4):456-463. https://doi.org/10.1093/ageing/afr007
60. Zuccala G, Onder G, Pedone C, Cesari M, Landi F, Bernabei R, Cocchi A (2001) Dose-related impact of alcohol consumption on cognitive function in advanced age: results of a multicenter survey. Alcohol Clin Exp Res 25(12):1743-1748

61. Beydoun MA, Beydoun HA, Gamaldo AA, Teel A, Zonderman AB, Wang Y (2014) Epidemiologic studies of modifiable factors associated with cognition and dementia: systematic review and meta-analysis. BMC Public Health 14:643. https://doi. org/10.1186/1471-2458-14-643

62. Jonnalagadda SS, Harnack L, Liu RH, McKeown N, Seal C, Liu S, Fahey GC (1022s) Putting the whole grain puzzle together: health benefits associated with whole grains-summary of American Society for Nutrition 2010 Satellite Symposium. J Nutr 141(5):1011s-1022s. https://doi.org/10.3945/jn.110.132944

63. Bechthold A, Boeing H, Schwedhelm C, Hoffmann G, Knuppel S, Iqbal K, De Henauw S, Michels N, Devleesschauwer B, Schlesinger S, Schwingshackl L (2019) Food groups and risk of coronary heart disease, stroke and heart failure: a systematic review and dose-response meta-analysis of prospective studies. Crit Rev Food Sci Nutr 59(7):1071-1090. https://doi.org/10.1080/10408 398.2017.1392288

64. Dong L, Xiao R, Cai C, Xu Z, Wang S, Pan L, Yuan L (2016) Diet, lifestyle and cognitive function in old Chinese adults. Arch Gerontol Geriatr 63:36-42. https://doi.org/10.1016/j.archg er.2015.12.003

65. Shakersain B, Rizzuto D, Larsson SC, Faxen-Irving G, Fratiglioni L, Xu WL (2018) The Nordic prudent diet reduces risk of cognitive decline in the Swedish older adults: a population-based cohort study. Nutrients 10:2. https://doi.org/10.3390/nu10020229

66. Nooyens AC, Bueno-de-Mesquita HB, van Boxtel MP, van Gelder BM, Verhagen H, Verschuren WM (2011) Fruit and vegetable intake and cognitive decline in middle-aged men and women: the Doetinchem Cohort Study. Br J Nutr 106(5):752-761. https://doi. org/10.1017/s0007114511001024

67. Samieri C, Okereke OI, Devore EE, Grodstein F (2013) Longterm adherence to the Mediterranean diet is associated with overall cognitive status, but not cognitive decline, in women. J Nutr 143(4):493-499. https://doi.org/10.3945/jn.112.169896

68. O'Brien J, Okereke O, Devore E, Rosner B, Breteler M, Grodstein $F$ (2014) Long-term intake of nuts in relation to cognitive function in older women. J Nutr Health Aging 18(5):496-502. https://doi. org/10.1007/s12603-014-0014-6

69. Arsenault LN, Matthan N, Scott TM, Dallal G, Lichtenstein AH, Folstein MF, Rosenberg I, Tucker KL (2009) Validity of estimated dietary eicosapentaenoic acid and docosahexaenoic acid intakes determined by interviewer-administered food frequency questionnaire among older adults with mild-to-moderate cognitive impairment or dementia. Am J Epidemiol 170(1):95-103. https://doi. org/10.1093/aje/kwp089

70. Willett WC, Howe GR, Kushi LH (1228S) Adjustment for total energy intake in epidemiologic studies. Am J Clin Nutr 65(4 Suppl):1220S-1228S. https://doi.org/10.1093/ajcn/65.4.1220S

71. Rothman KJ (2002) Epidemiology — an introduction. Oxford University Press, New York 


\section{Affiliations}

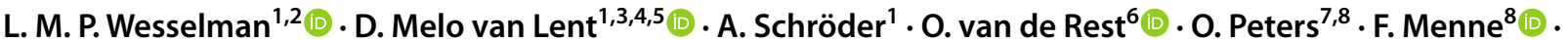 M. Fuentes ${ }^{8}$. J. Priller ${ }^{7,9}$. E. J. Spruth ${ }^{7,9}$. S. Altenstein ${ }^{9}$. A. Schneider ${ }^{1,10} \cdot$ K. Fließbach $^{1,10} \cdot$ S. Roeske ${ }^{1}$.

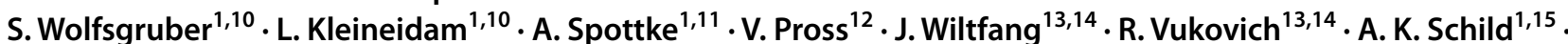

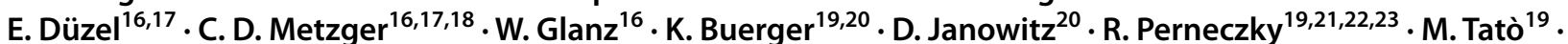

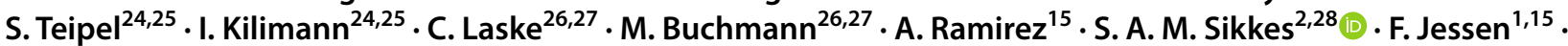 W. M. van der Flier ${ }^{2,29}$. M. Wagner ${ }^{1,10}$}

M. Wagner

michael.wagner@dzne.de

1 German Center for Neurodegenerative Disorders (DZNE), Bonn, Venusberg-Campus 1, 53127 Bonn, Germany

2 Department of Neurology, Alzheimer Center Amsterdam, Amsterdam Neuroscience, Vrije Universiteit Amsterdam, Amsterdam UMC, Amsterdam, The Netherlands

3 The Glenn Biggs Institute for Alzheimer's and Neurodegenerative Diseases, UT Health, San Antonio, TX, USA

4 Department of Neurology, Boston University, Boston, MA, USA

5 The Framingham Heart Study, Framingham, MA, USA

6 Division of Human Nutrition and Health, Wageningen University and Research, Wageningen, The Netherlands

7 German Center for Neurodegenerative Diseases (DZNE), Berlin, Germany

8 Charité-Universitätsmedizin Berlin, corporate member of Freie Universität Berlin, Humboldt-Universität zu Berlin, and Berlin Institute of Health, Institute of Psychiatry and Psychotherapy, Hindenburgdamm 30, 12203 Berlin, Germany

9 Department of Psychiatry and Psychotherapy, Charité, Charitéplatz 1, 10117 Berlin, Germany

10 Department for Neurodegenerative Diseases and Geriatric Psychiatry, University Hospital Bonn, Venusberg-Campus 1, 53127 Bonn, Germany

11 Department of Neurology, University of Bonn, Venusberg-Campus 1, 53127 Bonn, Germany

12 Study Center Bonn, Medical Faculty, Venusberg-Campus 1, 53127 Bonn, Germany

13 German Center for Neurodegenerative Diseases (DZNE), Goettingen, Germany

14 Department of Psychiatry and Psychotherapy, University Medical Center Goettingen, University of Goettingen, Von-Siebold-Str. 5, 37075 Goettingen, Germany

15 Department of Psychiatry, University of Cologne, Medical Faculty, Kerpener Strasse 62, 50924 Cologne, Germany
16 German Center for Neurodegenerative Diseases (DZNE), Magdeburg, Germany

17 Institute of Cognitive Neurology and Dementia Research (IKND), Otto-Von-Guericke University, Magdeburg, Germany

18 Department of Psychiatry and Psychotherapy, Otto-Von-Guericke University, Magdeburg, Germany

19 German Center for Neurodegenerative Diseases (DZNE, Munich), Feodor-Lynen-Strasse 17, 81377 Munich, Germany

20 Institute for Stroke and Dementia Research (ISD), University Hospital, LMU Munich, Feodor-Lynen-Strasse 17, 81377 Munich, Germany

21 Department of Psychiatry and Psychotherapy, University Hospital, LMU Munich, Munich, Germany

22 Munich Cluster for Systems Neurology (SyNergy) Munich, Munich, Germany

23 Ageing Epidemiology Research Unit (AGE), School of Public Health, Imperial College London, London, UK

24 German Center for Neurodegenerative Diseases (DZNE), Rostock, Germany

25 Department of Psychosomatic Medicine, Rostock University Medical Center, Gehlsheimer Str. 20, 18147 Rostock, Germany

26 German Center for Neurodegenerative Diseases (DZNE), Tübingen, Germany

27 Section for Dementia Research, Hertie Institute for Clinical Brain Research and Department of Psychiatry and Psychotherapy, University of Tübingen, Tübingen, Germany

28 Clinical Developmental Psychology and Clinical Neuropsychology, Faculty of Behavioural and Movement Sciences (FGB), Vrije University Amsterdam, Amsterdam, The Netherlands

29 Department of Epidemiology and Biostatistics, Amsterdam Neuroscience, Vrije Universiteit Amsterdam, Amsterdam UMC, Amsterdam, The Netherlands 